\title{
A DOENÇA NA SOCIEDADE COMO ENTIDADE E COMO PROCESSO: SUBSÍDIOS PARA PENSAR A EPIDEMIOLOGIA.
}

\author{
José Ricardo de Carvalho Mesquita Ayres(*)
}

\section{Resumo:}

Este artigo busca na "oscilaçāo" histórica da compreensão da doença na sociedade, como entidade ou como processo, elementos para a reflexāo acerca dos impasses e exigências vividos hoje pelos saberes e práticas da epidemiologia, por referência à proposição da construção de uma sociedade mais livre e justa.

Superando o caráter metafísico das concepçōes ontológicas pré-modernas, as traduçōes processuais da epidemiologia tornaram-se nucleares a todo o conhecimento objetivo e intervenção prática sobre a dimensão social da doença, a partir do século XIX. No entanto, ao consolidarem socialmente essa posição, os métodos e objetos da ciência epidemiológica assumiram o estatuto prático de verdadeiros entes. São exploradas as raízes e as contradições desse "processualismo" que acaba por negar a sua própria natureza processual.

Destaca-se a potencial contribuição de uma "concepção consensual de verdade" na superação do conteúdo de "irracionalismo" que, não obstante inegáveis méritos, esse paroxismo processual do saber epidemiológico, tem conferido à práxis sanitária.

${ }^{*}$ ) Médico sanitarista, mestre em Medicina Preventiva - Departamento de Medicina Preventiva da Faculdade de Medicina da USP / Centro de Saúde Escola do Butantā. 


\title{
A DOENÇA NA SOCIEDADE COMO ENTIDADE E COMO PROCESSO: SUBSÍDIOS PARA PENSAR A EPIDEMIOLOGIA.
}

\begin{abstract}
"Tenho algo a descobrir de próprio, algo que ninguém possui a tarefa de descobrir em meu lugar. Se minha existência tem um sentido, se ela não é vã, tenho uma posição no ser que é um convite a colocar uma questāo que ninguém pode colocar no meu lugar. A estreiteza de minha condição, de minha informação, de meus encontros e de minhas leituras já esboça a perspectiva finita de minha vocaçāo de verdade. No entanto, por outro lado, procurar a verdade quer dizer que aspiro a dizer uma palavra válida para todos, que se destaca sobre o fundo de minha situação como um universal. Não quero inventar, dizer o que me agrada, mas aquilo que é".
\end{abstract}

(Paul Ricoeur)

\section{INTRODUÇÃO}

O conhecimento produzido, ao longo da história, acerca dos fenômenos coletivos da saúde e da doença podem ser identificados, em termos gerais, a dois pólos abstratos: o pólo ontológico e o pólo processual ${ }^{(18)}$. Tais polaridades designam experiências com dimensōes diversas da doença na vida social; sintetizam diferentes modos como os homens têm se relacionado com as condiçōes adversas, no campo da Saúde Pública, para a realização de suas necessidades e ideais. 
Doença-entidade e doença-processo são modalidades historicamente distintas de apreensão teórica da doença na sociedade, isto é, delimitam-se no tempo e no espaço de modo tal que reconhecemos cada uma delas como parte de determinadas formas de organização social da vida do homem, fora das quais, em conseqüência, estas modalidades têm obscurecida a compreensão adequada dos seus conteúdos.

Não se quer dizer, com isso, que estas distintas formas de apreender a saúde na sociedade nada tenham a ver uma com a outra, e que não se encontre, em cada uma delas, qualquer traço daquela que se the contrasta. Ao contrário, se é possível nos referirmos a duas polaridades históricas é porque há um solo comum, uma mesma linguagem básica que autoriza (e evidencia) o contraste. Esta linguagem, este solo comum, não é mais nem menos do que a viva expressão de uma íntima convivência e mútua influência dos conceitos que as caracterizam.

No seu contínuo processo de transformação, contudo, antigos e novos conceitos articulam-se de tal modo em teorias e práticas que adquirem, em certo momento, uma identidade diversa daquela que possuíam em períodos anteriores, configurando modalidades distinguíveis historicamente ${ }^{(6)}$.

É justamente essa historicidade que se quer explorar nesta breve reflexão. Procuremos examinar como a apreensão do movimento de configuração e transformação destes diferentes modos de conceituar a saúde e a doença na sociedade (ontológico e processual) iluminam o esforço que vem sendo realizado na Saúde Coletiva para a construção de conhecimentos científicos progressiva e 
igualitariamente emancipadores no campo sanitário. Nesse sentido, comecemos, argüindo-nos acerca das razões e do modo pelos quais, entre continuidades e descontinuidades nos diversos conceitos de saúde, as teorias modernas sobre a doença abandonaram a preocupação com a caracterização de entidades patológicas e passaram a se ocupar de processos patológicos na construção do conhecimento em geral. Em seguida, abordaremos a questão na perspectiva particular do conhecimento em saúde coletiva.

"O QUE É?", "COMO É?".

$\mathrm{Na}$ atualidade, toda vez que nos perguntam o que é determinada doença, queiramos ou não, percebamos ou não, respondemos como é esta doença ${ }^{(4)}$. Respondemos, sempre que indagados nesse sentido, com a descrição de um quadro de eventos que configura o processo orgânico ou psíquico em questão. Evento a + evento $b+$ evento $c$ correspondem a identidade da doença $x$ ou das doenças $x$. Mesmo quando há um "vilāo" que empresta sua identidade à doença à qual está associado, tornando desnecessária a descrição sindrômica ou fisiopatológica para que se a identifique, é ainda de processos que estaremos falando, pois os agentes causais são definidos em função dos seus próprios processos vitais e por aqueles de interação com os seres humanos. 
A tuberculose, por exemplo, é a doença causada pelo bacilo de Koch, que se define, em termos mínimos, por ser o bacilo álcool-ácido resistente que provoca, ao entrar em contacto com o organismo humano, uma reação inflamatória específica. Se perguntarmos o que é esta reação obteremos como resposta a descrição do modo como ela ocorre. Se continuarmos insistindo em definiçōes, mais e mais processos serão desfiados à nossa frente, até o limite em que nossos sentidos, armados de todos os instrumentos já desenvolvidos, puderem ser certificados do modo como as coisas acontecem.

Anatomia, fisiologia, bioquímica, biofísica, propedêutica, terapêutica, pediatria, oftalmologia, fisiatria, etc., etc. etc... . Todo o conhecimento que, leigos ou "experts", usamos cotidianamente apresenta essa mesma vocação para responder às perguntas que o homem tem precisado fazer-se acerca da saúde, recorrendo ao modo como as coisas são.

"Não terá sido sempre assim?", poderemos nos estar perguntando, com justa razão, pois, a uma primeira aproximação, pode parecer-nos inconcebível que se tente responder a qualquer indagaçāo do homem a respeito das verdades objetivas de seu mundo sem que esta resposta se baseie rigorosamente no "modo como as coisas acontecem".

O que nos dificulta conceber uma outra alternativa para buscar essas verdades é o nosso horizonte epistêmico ${ }^{(11)}$. Homens de nosso tempo, entendemos a possibilidade de conhecer as verdades do mundo limitada àqueles elementos de que nossos cinco sentidos podem se asseverar. O raciocínio abstrato, a intuição, os 
valores, todo o resto, quando se trata da verdade objetiva, fica sob a rígida vigilância dessas sentinelas.

Ao atribuir aos sentidos a primazia na garantia da verdade, o que a nossa modernidade apresenta de mais característico é o fato de que os sentidos não são apenas instrumentos de conhecimento, mas também, e principalmente, são os juízes do mesmo; são o critério último a que deve ser submetida qualquer afirmação que aspire à condição de verdade ${ }^{(26)}$. Mas isso não foi sempre assim, claro.

$\mathrm{Na}$ realidade, alguns dos grandes nomes da medicina, pilares sobre os quais erigiu-se este vasto campo de saber, comungavam outras concepçōes, igualmente objetivas, igualmente legítimas à sua época, mas radicalmente diferentes quanto ao estatuto atribuído aos sentidos humanos na construção do conhecimento. De fato, até a Modernidade, e não só na medicina, nāo era o empírico - a realidade experimentada pelos sentidos - que dava a palavra final acerca da verdade, embora fosse um testemunho indispensável. Antes, era o raciocínio formal, segundo lógicas abstratas de diferentes espécies, que autorizava os discursos dessa natureza. Assim, o modo como as coisas acontecem diante dos sentidos não representava, então, senão um entre os inúmeros aspectos que caracterizavam a identidade das mesmas $^{(11)}$.

Um exemplo simples, extraído de um momento de transição na história da medicina ${ }^{(10)}$, ilustra de forma bastante elucidativa esta diferença. No século XVI o espanhol Miguel Servet (1511-1553), fugindo da feroz Inquisição de seu país de 
origem exilou-se em Paris, onde passou a estudar a arte da medicina e suas ciências, sendo condiscípulo do célebre anatomista renascentista Vesálio (1414-1564).

Vesálio, profundo conhecedor e renovador da anatomia galênica, não conhecia a "pequena circulação" ou a circulação pulmonar. Para Vesálio, como para Galeno, o sangue vinha do fígado ao ventrículo direito e passava ao ventrículo esquerdo através de poros supostamente existentes no septo interventricular, sendo oxigenado no ventrículo esquerdo. $O$ ar, segundo a concepção galênica, seria trazido dos pulmões até o coração pela "artéria venosa" (veia pulmonar); a "veia arteriosa" (artéria pulmonar) teria apenas a função de levar sangue do coração aos pulmões para nutrir esses órgãos.

Servet, instigado por peculiares motivaçōes de ordem religiosa (a busca do trajeto orgânico do "sopro vital"), dedicou-se a estudar a anatomia do coração e dos grandes vasos torácicos, "descobrindo" a pequena circulação (na verdade ela já havia sido descrita, sem muita repercussão, por Ibn-an-Nafís, na ldade Média). Apesar de contemporâneos, Vesálio, com toda a excelência e detalhismo descritivo de sua anatomia, divergia de Servet, e, mesmo não observando em seus estudos qualquer orifício no septo interventricular, explicava por mecanismos de transudação o pressuposto galênico da passagem sanguínea entre os ventrículos, mantendo inalteradas as concepções do mestre.

Como foi possivel tal discordância, devemos nos perguntar, se ambos, para suas afirmaçōes, recorriam ao mesmo instrumento de conhecimento: a habilidade de suas mãos e o testemunho de seus olhos? A diferença está em que, apesar de já 
ser, em muitos sentidos, um homem dos novos tempos, Vesálio procurava na anatomia, "sob o peso de Galeno"(11), as evidências, o aprofundamento, o detalhamento daquilo que era possível deduzir dos princípios que, durante muitos séculos, se sabia regerem a vida humana. Já Servet buscava elementos empíricos que o levassem, indutivamente, ao desvelamento de fatos até então desconhecidos. Ambos usavam os sentidos, de ambos estes eram preciosos instrumentos, mas para o primeiro funcionavam como testemunhas, para o segundo como juízes.

Assim é que Vesálio "decidira" que havia transudação no septo interventricular porque era isto o que podia ser deduzido da pressuposta necessidade de que o sangue vindo do fígado pudesse chegar à aorta e ser distribuída para todo o corpo. Servet, ao contrário, questionou a teoria existente porque as evidências anatômicas apontavam outra coisa. Para este, o sangue nāo poderia passar do ventrículo direito ao esquerdo pela simples razão de que não havia passagens visíveis, e o que chamou a sua atenção para a possibilidade da circulação pulmonar foi o tamanho da "veia arteriosa", excessivamente calibrosa, segundo Servet, para ter como função apenas a nutrição dos pulmōes, como se acreditava.

$\mathrm{Na}$ verdade, mais do que uma mudança nos conhecimentos de um setor da anatomia humana, estava em questão, nessa divergência, uma verdadeira revolução do saber ${ }^{(16)}$. Novas concepções, novos conceitos, novas formas de conceber a verdade se anunciavam, não só com Servet, mas, em outros aspectos, com o próprio Vesálio e com todos aqueles que propunham como corolários básicos do conhecimento verdadeiro a indução empiricamente fundada, e concebida a partir das injunções práticas da experiência objetiva do homem. 
No mesmo movimento em que se redimensiona o papel exercido pelos sentidos e se valoriza a perspectiva secular na construção do conhecimento, a objetividade é deslocada do pólo ontológico para o processual. O que o homem pode (e basta-lhe) conhecer é a dinâmica do real, não sua razão de ser.

Essa passagem é tida como o marco cultural da transição da ldade Média para a Idade Moderna na história da civilização ocidental. Como sabemos, esta revolução cultural é, por sua vez, a contrapartida de profundas mudanças ocorridas no modo de reprodução material das sociedades ocidentais, correspondendo à passagem do modo de produção feudal ao modo de produção capitalista, e sua correspondente ordem social.

Ora, se na emergente ordem social capitalista o homem e seu trabalho são alçados ao centro da cena política, econômica e social, sobrepujando os valores transcendentais e místicos que legitimavam a ordem feudal, é compreensível que o conhecimento também se fundamente naquilo que é inerente e acessível a todo e qualquer homem: a objetividade dos seus sentidos. Os êxitos práticos obtidos por intermédio desta objetividade foram, mesmo, uma das armas com que os homens fizeram ruir o castelo do feudalismo.

$\mathrm{Na}$ ordem feudal, a razão melhor realizava sua "aptidão" quanto mais fosse capaz de enxergar no mundo as marcas de sua origem transcendental. Ou seja, a partir de Deus, a origem primeira da existência, todas as coisas no mundo, inclusive o homem, se tornavam criaturas, entes cujo lugar no universo era criado por um Ser a eles superior, e só podia ser entendido por meio dessa ascendência primária. 
Conhecer algo era sinônimo de saber o lugar que esse algo ocupava no plano da criação universal. Em função da finitude do homem, das limitaçōes de sua razão, esse lugar precisava ser pacientemente decifrado nos signos materiais captados por nossos sentidos e interpretados à luz de teorias gerais acerca da existência ${ }^{(11)}$.

Responder sobre a identidade das doenças antes da ldade Moderna terá tido, portanto, respostas muito diferentes daquelas que damos hoje, e não por um simples acúmulo maior de conhecimentos que teríamos atualmente, mas principalmente porque a natureza das respostas precisava ser mesmo muito diferente. Seria inconcebível responder a um médico do medievo acerca da identidade de uma doença descrevendo-Ihe um processo. Ele muito estranharia a resposta, e, no mínimo, a consideraria algo prolixa e inconclusiva. Ele, inversamente, abstrairia de determinados signos materiais associados à doença em questão a apreensão da identidade da mesma, e, a partir desta, faria decorrer a compreensão dos processos que principiaríamos por descrever.

Mas não só no processo de construção do conhecimento podemos nos aperceber das radicais diferenças entre as duas formas de entendimento dos fenômenos patológicos. O momento da ação, da intervenção, talvez seja ainda mais eloqüente nesse sentido.

Quando, por exemplo, o médico classificava um doente segundo a leitura medieval da tipologia galênica ${ }^{(10)}$ como sendo de tipo sanguíneo, colérico, fleumático ou melancólico (todos os indivíduos eram classificáveis segundo essas quatro categorias fechadas), ele o fazia com base em certos sinais físicos e psíquicos 
apresentados pelo indivíduo, e o associava, por meio destes sinais, às qualidades básicas de seu tipo, interpretadas segundo afinidades encontradas em todas os entes existentes, em toda as esferas da criação ${ }^{(11)}$.

Assim como, para o homem do medievo, os quatro elementos básicos - 0 fogo, a água, o ar e a terra - guardavam relação com toda a matéria, também as características não materiais dos seres vivos estavam associadas às "qualidades primárias" expressas por esses elementos. Saber com que elementos estava associado o temperamento do paciente significava, imediatamente, conhecer o tipo de patologia que seu corpo tendia a desenvolver e, por conseguinte, a natureza da intervenção terapêutica que poderia surtir o efeito mais adequado ${ }^{(9,12)}$.

Em outras palavras, quando a identidade nosológica é dada por qualidades essenciais, o diagnóstico, o prognóstico e a terapêutica tornam-se momentos indissociáveis do movimento de identificação da entidade patológica. $O$ processo concreto que a doença descreverá será um elemento ratificador da natureza assinalada nas características da entidade patológica e retificador de eventuais "equívocos" na sua identificação.

Diversas eram as formas pelas quais a medicina se apercebia das afinidades dos signos materiais e imateriais das doenças e dos doentes com as qualidades essenciais de onde se lhes abstraía a identidade ${ }^{(11)}$ : similaridade de formas, simultaneidade de eventos, proximidade topográfica, comportamentos análogos, antagonismos fenomenológicos, etc.. O doente sanguíneo beneficia-se da sangria porque esta aplaca um pouco a exacerbação das qualidades que o excesso 
desse elemento transmite ao doente de tal natureza; a certeza de que o acônito faz bem aos olhos vem da aparência das sementes deste vegetal, verdadeiras reproduções do órgão da visão; as circunvoluções da noz denunciam sua afinidade com o cérebro humano; a ocorrência simultânea de um quadro mórbido em diversos indivíduos num mesmo lugar e tempo indica a natureza atmosférico-cósmico-terrestre das doenças, radicalmente diferente daquelas que se assentam sobre suscetibilidades individuais; e assim por diante.

Seja no momento do conhecimento, seja no da intervenção terapêutica, vemos, portanto, que a doença-entidade e a doença-processo constituem construçōes conceituais distintas, maneiras profundamente diversas do homem problematizar suas questões de saúde, de formular e responder às perguntas postas pelas necessidades públicas e privadas relacionadas a esta dimensão da existência.

Examinadas sinteticamente as diferenças na objetivação da doença em geral, antes e após a passagem à Modernidade, detenhamo-nos agora no plano da saúde coletiva. Examinemos como as polaridades ontológica e processual se manifestam e repercutem no campo da produção de conhecimento em Saúde Pública.

\section{EPIDEMIA, EPIDÊMICO, EPIDEMIOLOGIA.}

Examinemos a afirmação de que a ocorrência de um quadro mórbido em diversos indivíduos num mesmo lugar e tempo indicava, até há algum tempo atrás, uma natureza peculiar da doença, chamada "atmosférico-cósmico-terrestre". 
Vejamos o que Ignaz Semmelweiss (1818-1865) nos diz a respeito, falando a propósito da febre puerperal:

"Em geral, a desafortunada confusão entre os conceitos de doença epidêmica e endêmica retardaram o descobrimento da verdadeira causa da febre puerperal.

Para classificar a febre puerperal como doença epidêmica ou endêmica é preciso ignorar por completo o número de pacientes que adoeceram ou morreram. A causa da doença ou morte determina se a enfermidade é epidêmica ou endêmica. A febre puerperal epidêmica é induzida por influências atmosférico-cósmico-terrestres; o conceito de uma epidemia não estipula se são uma ou cem pessoas as que adoecem. Se a febre puerperal é causada por fatores endêmicos, quer dizer, por fatores cuja atuação se limita a uma localização específica, então a febre puerperal é endêmica, e não importa se são um ou cem os indivíduos que adoecem. Esta é a conseqüência lógica dos conceitos de doença epidêmica e endêmica. Não obstante, para classificar esta doença como uma ou outra, as comissōes não consideraram a causa aparente, mas somente o número de casos. Devido a muitas mulheres terem adoecido e morrido, se a identificou como epidêmica." (24)

Embora Semmelweiss tenha vivido em pleno século $X I X$, quando as traduçōes teóricas da doença como um processo já eram amplamente divulgadas e aceitas, podemos ainda notar, no cerne da sua argumentação, elementos da 
concepção das doenças enquanto entidades. Semmelweiss é considerado um dos primeiros "contagionistas"(22), ou seja, um dentre aqueles que, já avançando concepções processuais dos problemas sanitários, interpretavam as doenças que acometiam as coletividades segundo a perspectiva da transmissão de processos patológicos de indivíduo a indivíduo.

Os contagionistas tinham nos adeptos das teorias miasmáticas seus constantes contendores ${ }^{(22)}$. Para estes últimos, as doenças precisavam ser pensadas como fatos em si mesmos, como fenômenos com características particulares, expressas nas formas de suas manifestaçōes. Quando se referiam a influências atmosférico-cósmico-terrestres, os médicos e pensadores da aurora da medicina científica moderna lançavam mão de concepções hegemônicas nas teorias miasmáticas dominantes até então, que viam na doença coletiva uma natureza própria, uma entidade autônoma, independente da natureza do homem em sua conceituação. Era uma "criatura" como o próprio homem.

É importante destacar a profunda distinção que esta noção de entidade estabelece entre a doença e o homem. São dois seres relativamente estranhos um ao outro, ocupam lugares diferentes, seja, primeiramente, num "Plano da Criação" divina do mundo, seja, posteriormente, numa classificação natural das espécies ${ }^{(12)}$.

Ora, se há distinção entre o ser do homem e o da doença, haverá também uma descontinuidade conceitual entre o homem que está doente e o homem que está são, entre o normal e o patológico, entre populações sadias e populações "acometidas". Desta descontinuidade há resquícios, ainda, no excerto supracitado de 
Semmelweiss, quando este distingue pela causalidade o conceito de doença epidêmica: o endêmico encontra-se mais próximo da natureza humana, o epidêmico mais distante, a natureza deste último é atmosférico-cósmico-terrestre. $\mathrm{O}$ alto número de casos, no raciocínio de Semmelweiss, deve ser tomado apenas como um indicador, nem sempre fidedigno, de que se está diante de um quadro cuja causalidade está além das possibilidades de intervenção do homem, um quadro de "natureza epidêmica".

Bem, quanto mais avança a Modernidade e seu conjunto de necessidades sociais, econômicas, políticas e culturais, o espaço ideológico para essa distinção qualitativa entre o ser do homem e o ser das coisas à sua volta vai diminuindo, como pontuamos acima. Alçando-se ao centro da cena, o homem estabelece imediatamente uma homogeneidade qualitativa entre o seu ser e o ser das coisas, subordinando ao juízo baseado no seu ser a apreensão do ser das coisas.

Vista a partir da perspectiva antropocêntrica e empiricista que passa a dominar o pensamento ocidental, o conceito de doença coletiva vai abandonando progressivamente as descontinuidades conceituais entre sadio e doente, entre coletivo e individual, entre endêmico e epidêmico. Doença passa a ser traduzida como anormalidade, ou seja, como alteração desfavorável de uma condição encontrada no homem comum, ou normal ${ }^{(8)}$. A doença na sociedade passa a designar restritivamente conjuntos de indivíduos doentes. Epidêmico e endêmico passam a referir-se ao comportamento quantitativo das anormalidades nos indivíduos. 
Quando John Snow, com o trabalho símbolo das modernas traduçōes conceituais da doença na sociedade ${ }^{(25)}$, explica e domina a epidemia do cólera na Inglaterra vitoriana, com base na idéia de transmissão inter-individual de condições desfavoráveis às funções normais do organismo humano, formaliza-se um dos primeiros entre os inúmeros sucessos do contagionismo na satisfação de necessidades postas para o conhecimento em saúde na ordem social capitalista ${ }^{(4)}$.

A partir do contagionismo, o conceito de "epidêmico" associa-se à magnitude da freqüência de doenças (a-normalidades), ou de determinadas condições de saúde de interesse, e não à identidade causal dessas doenças. Ou seja, a ciência moderna que se desenvolveu no núcleo das práticas e saberes relacionados à saúde na sociedade, a epidemiologia, não veio para ocupar-se da investigação do "o que é?" a doença na sociedade, dos diferentes "seres" das doenças coletivas, mas sim dos modos como determinadas condições humanas tornam-se freqüentes e relevantes o suficiente para configurarem preocupações públicas. $A$ tal ponto comungamos hoje dessa abordagem, que qualquer um de nós teria dificuldade de argumentar com Semmelweiss a respeito de epidemias e endemias. De modo praticamente inverso ao que se processava com o médico de Viena, no núcleo de nossa definição estaria o número de casos, e fluiria daí para os mecanismos causais a direção lógica do nosso raciocínio.

A epidemiologia configurou-se historicamente, em suma, como uma sistematização formal da problematização empiricista da doença coletiva nos moldes da questão "como é?". Da perspectiva rigorosamente epistêmica ela só se formaliza como ciência enquanto tradutora da doença como processo. 


\section{O PROCESSO COMO ENTIDADE.}

Ao formalizar-se cientificamente em moldes processuais, os construtos teóricos da epidemiologia assumem hoje, entretanto, o estatuto prático de verdadeiras entidades, tanto no que diz respeito aos seus objetos, quanto no que se refere ao seu instrumental. É que se a doença como processo foi o resultado e o instrumento de superação de formas de problematização da doença na sociedade que estavam em desacordo com as mudanças históricas das quais o homem fez-se sujeito na aurora da Modernidade, no momento de consolidarem-se no âmbito das novas práticas sociais que ajudaram a construir, a epidemiologia e o epidemiológico assumem feiçōes de elementos de uma "ordem científica" absoluta e soberana, consubstancial com a nova ordem social consolidada.

Quanto mais amadurecem as traduções processuais operadas pela epidemiologia, e quanto mais êxito e legitimidade tendem a alcançar em termos sociais, maiores se tornam as chances de que tomemos seus construtos (objetos e instrumentos) como "coisas em si", entidades cujos significados absolutos só nos cabe desvelar e aceitar. É assim quando vemos a doença coletiva como um mal abstrato que se abate sobre uma sociedade também abstrata, e não como o resultado de descrições de indivíduos concretos acerca de males da vida em sociedades concretas. É assim também quando enxergamos nos métodos quantitativistas o acesso garantido à Verdade, ao invés dos mecanismos circunstanciados e circunstanciais de produção de enunciados verdadeiros, o que em realidade são(5). 
Troque-se Deus pela tecnologia (a lógica do fazer) e as qualidades essenciais pelas regularidades objetivas e está produzida uma espécie de versão "yuppie" do "Plano da Criação", no qual a doença na sociedade torna-se uma espécie de entidade pós-moderna.

Felizmente, se os êxitos da epidemiologia, como de resto o de outras ciências da saúde, tendem a fixar no plano do simbólico a imagem da doença-entidade (e também do saber-entidade), os seus correlativos, e inevitáveis fracassos atuam no sentido inverso. Quando determinados sujeitos, a partir de suas perspectivas objetivas, percebem insuficiências, inadequaçōes ou deformaçōes na epidemiologia, por referência ao que ela "promete" como técnica e como ciência, caminha-se no sentido da "desconstrução" da imagem do saber-entidade. Como nenhuma ciência pode estar isenta às contradições entre as diversas situações objetivas dos homens vivendo em sociedade, a epidemiologia-entidade (e a doença coletiva- entidade) fica mais e mais exposta, à medida de seu amadurecimento, à oportunidade de desmitificação. Quanto mais clara a promessa mais exigente é a cobrança.

A epidemiologia de hoje já é pródiga em críticas aos seus axiomas científicos $^{(3)}$. As acentuadas diferenças na distribuição da doença nos diversos segmentos sociais; a timidez dos progressos técnicos no campo da Saúde Pública; as mudanças nos perfis sanitários, com a enorme importância das doenças crônico-degenerativas e das "velhas" e novas infecciosas; o desenvolvimento paralelo de outros campos de conhecimento humano; o surgimento de novas possibilidades técnicas, como o uso da informática; a massificação e as transformaçōes qualitativas nos padrões de consumo dos indivíduos; etc., colocam possibilidades e, 
principalmente, exigências diversificadas, levando a epidemiologia a reenfrentar antigas questōes de identidade.

Claro que hoje não se tratará mais da contenda entre miasma e contágio, muito menos de se reivindicar Deus e as qualidades primárias como pilares do conhecimento, mas questóes do tipo "o que é?" e "como é?" voltam a tensionar-se mutuamente, ainda que em patamares muito diferentes daqueles em que se enfrentaram anteriormente. As polêmicas, candentes na epidemiologia, acerca de aspectos como determinação, apreensão objetiva e explicação racional, são a expressão desse tensionamento em diferentes níveis.

É de se perguntar, por exemplo, até que ponto e sobre quais aspectos pode a epidemiologia aprofundar o caráter processual da apreensão teórica e legitimação científica de seu objeto. $O$ exame dos conceitos básicos que esta ciência tem produzido revela que a tradução processual que estes operam deixam de dar conta de aspectos fundamentais para a compreensão e intervenção na determinação dos problemas de que tratam, tornando-a, na prática, um procedimento quantificador de eventos explicados em outros campos de saber ${ }^{(4,19)}$. Não é isso, em última análise, que está expresso no fato, acima assinalado, de que os termos epidemia e epidêmico referem-se hoje a um comportamento substantivamente quantitativo, esvaziados de qualquer discriminação qualitativa, determinística, do objeto de que tratam?

O fato da quantificação dos fenômenos de saúde ter se tornado nuclear na configuração e legitimação da epidemiologia como um campo científico específico não significa que resida aí a identidade de seu objeto (e, portanto, da epidemiologia 
como ciência). Assim como as ciências ditas naturais, como a biologia, encontram nas constantes físico-químicas o fundamento objetivo de descriçōes processuais que, enquanto tais, não se confundem com as da física e as da química, mas configuram um campo de determinaçāo propriamente biológico ${ }^{(7)}$, também a epidemiologia precisa aprofundar suas técnicas e fundamentos objetivos sem perder de vista a especificidade dos processos que estuda, a esfera determinística própria de seu objeto ${ }^{(2)}$.

O "como é?" da epidemiologia não pode, efetivamente, perder-se de certos "o que é?" que estão, ainda que de forma velada, na raiz de todo campo de conhecimento objetivo. Do contrário, ela precisará conformar-se com o destino de se tornar apenas um conjunto de técnicas aplicadas.

\section{ONTOLOGIAS E PROCESSOS.}

A crítica ao caráter processual do conhecimento epidemiológico acerca da doença na sociedade, que permeou toda esta discussão, não deve ser entendida como rejeição, total ou parcial, do arsenal teórico e metodológico que esta ciência veio desenvolvendo ao longo de sua história. O processo de "crítica", infortunadamente, quase sempre carreia essa conotação negativa, de rejeição do objeto sobre o qual é aplicada, quando deveria ser o contrário. A crítica, no sentido filosófico, só se detém sobre aquilo que de algum modo valoriza.

Em nosso caso, a questão que se quis destacar é que, através da dialética dos dois pólos conceituais que examinamos, é possível vislumbrar necessidades e 
possibilidades para a ciência epidemiológica que, "por dentro" da própria ciência não podemos "resolver".

Não obstante a impressão cotidiana dos epidemiólogos e sanitaristas, senso lato, de que a epidemiologia vem, mais e mais, descrevendo processos cujo significado concreto conhece cada vez menos, as tentativas estritamente científicas de diagnosticar e resolver esse problema têm sido infrutíferas. O positivismo, que abriu tantas fronteiras para o saber epidemiológico, não lhe concedeu esta prerrogativa (e nem a qualquer outra ciência sob sua égide).

"Enclausuradas" no agnosticismo de seus métodos, as ciências positivistas só podem discursar acerca de certezas: quais podemos afirmar que temos, e em que medida ${ }^{(1)}$. As "não-certezas"(*), frutos da diversidade dos homens e pré-requisito da aptidão profundamente humana de optar, são matéria sobre a qual estas ciências nada têm a dizer. Abdicar da "não-certeza" foi o tributo pago à Modernidade em troca da ilusão de verdades sem fiadores divinos ou humanos.

A vantagem da aproximação epistemológica, aqui utilizada, pela via da dimensão "práxica" do conhecimento, isto é, pelas injunções tecnopolíticas das compreensões ontológica e processual da doença na sociedade, está justamente na possibilidade que ela oferece de expandir e enriquecer o horizonte em relação ao qual a epidemiologia pode entender sua própria condição objetiva como ciência. O grande

$\left(^{\star}\right)$ Utiliza-se aqui essa espécie de neologismo como forma de evitar que se contraponha, equivocadamente, à idéia de certeza, aquela usualmente atribuída à de incerteza, qual seja, a de dúvida. A "no-certeza" quer se referir no à dúvida, tampouco a qualquer tipo de fé (que é um outro tipo de certeza), mas à esfera de relativa liberdade que dispe a razo do homem para atribuir valor à sua experiência sensível do mundo, e que, sendo valor, pe "subjúdice" os significados descritivos e prescritivos desta experiência. 
interesse deste tipo de abordagem está no resgate das "não-certezas" (aquelas observadas historicamente e as nossas próprias) envolvidas na práxis epidemiológica, as quais nos autorizam a perguntar: o que quero que a epidemiologia conheça, e como pode ela conhecer especificamente isto?

De fato, o aprimoramento estritamente técnico da ciência epidemiológica não garante uma articulação prática comprometida com a emancipação humana no campo sanitário, muito menos com a universalidade prometida pelo(s) positivismo(s). Há limites na dimensão técnica da ciência epidemiológica para a transformação de seu caráter prático ${ }^{(17)}$. E, embora só a afirmação deste limite não seja, em absoluto, ociosa na conjuntura atual das práticas sanitárias, é definitivamente preciso lançar-se nos caminhos da superação desse mito da eficácia técnica universal da ciência.

Parece claro que o abandono das concepções metafísicas da doença-entidade favoreceu a ampliação da qualidade de vida e da liberdade humana, pela maior e mais democrática intervenção permitida por uma razão secularizada no controle da doença na sociedade. Vimos, contudo, que essa secularização se fez às custas de um conhecimento que levou a busca da objetividade às fronteiras do irracionalismo, ao tratar construções processuais como entidades, frustrando parte substancial dos ideais emancipadores que estāo na raiz histórica do saber epidemiológico ${ }^{(4)}$. Mostra-se efetivamente necessário rever o significado desses dois pólos da conceituação da doença coletiva, de modo a obter certezas objetivas sobre a mesma sem negligenciar o caráter também objetivo das "não-certezas" envolvidas nas possibilidades de sua tradução teórica. 
Será que não podemos nos valer da objetividade das "não-certezas" para produzir conhecimento verdadeiro? Nāo será possível articular a eficácia tecnológica dos "como é?" à riqueza simbólica dos "o que é?" no conhecimento do que seja verdadeiramente a condição humana? Não será possivel discriminar diferentes "seres" nos processos humanos pelos quais a doença é concretamente experimentada na sociedade?

Recentes proposições filosóficas, que têm na obra de Habermas um de seus mais notáveis desenvolvimentos, postulam que não existe uma verdade universal, nem um modo universal de chegar à verdade. Compreendem a busca do esclarecimento, da emancipação do homem através de sua Razāo, como uma grande construção coletiva, um diálogo, sempre em curso, entre discursos diversos sobre o mundo, interpretações resultantes das particulares condições objetivas dos diferentes sujeitos humanos ${ }^{(13)}$.

Sob a perspectiva habermasiana, os discursos que descrevem o mundo aspirando expressar sua objetividade fundam-se em "nāo-certezas", legitimadas socialmente com base em três níveis de eficácia discursiva: na proposição de enunciados consistentes com a realidade (histórica) do mundo (contextual), na antecipação de condições necessárias para o bom êxito dos projetos sociais definidos nos contextos em que se conformam esses discursos e na sua capacidade de estabelecer comunicação efetiva, de gerar inter-subjetividades objetivas.

Contrapōe, desse modo, à idéia de uma verdade universal (seja ela absoluta, como queria o primeiro positivismo, ou quimérica, como a concebem os 
neo-positivistas) uma concepção consensual da verdade. Nesta, a intersubjetividade é o fundamento do conhecimento, e a Verdade é "negociada" a partir da capacidade de legitimação dos discursos de verdade dos diversos sujeitos. O discurso de verdade, como dissemos, demonstra suas "virtudes" na "negociação", em função de sua capacidade de expressar verdades dotadas de valor social, da possibilidade de instruir ações eficazes, nos diversos campos de aplicação prática desses valores e no êxito em estabelecer as interações adequadas à expressão criativa e não opressora desses valores.

Esta formulação parece abrir novas perspectivas para pensarmos os pólos ontológico e processual da epidemiologia. Ela permite, parafraseando Habermas, retraduzir a teoria sobre a doença na sociedade como "a caracterização formal de condiçōes necessárias para formas não antecipáveis de uma vida não fracassada". Em outros termos, a doença na sociedade pode ser pensada como processo na medida em que é traduzida em enunciados que renunciam à busca de uma verdade essencial e permanente de seu objeto, e como ontologia enquanto portadora de um Ser, constantemente refeito, que expressa uma identidade positiva, algo que se comporta como uma referência humana da própria existência, como uma negação da "vida não fracassada".

Por outro lado, a razão comunicativa de Habermas nos adverte para a amplitude e a complexidade do desafio do diálogo ontológico-processual na epidemiologia, pois ressalta o caráter social da produçāo do conhecimento e a necessidade de reconstruir as relações entre os sujeitos, não apenas no interior da cidade científica da saúde e da epidemiologia, mas no conjunto das relações sociais. 
Isso não significa, naturalmente, que devamos esperar a sociedade da plena justiça e liberdade para trabalharmos por e com uma epidemiologia renovada. Ao contrário, é a criação da pluralidade e efetividade de espaços concretos de diálogo entre os diversos projetos humanos, e a construção de mecanismos igualitários e criativos para a expressão desses projetos, que poderá, segundo a "aposta" na dimensão comunicativa da razão, construir sociedades mais justas e livres.

É importante destacar, nesse sentido, que, numa sociedade de desiguais, a busca da emancipação precisa considerar condiçōes concretas inapreensíveis, de modo exclusivo, pela dimensão interacional da razão humana ${ }^{(14)}$. Não faz sentido pensar na dimensão libertária de uma razão constituída a partir de interaçōes humanas livres de dominação sem considerar a alienação dos homens na reprodução material das sociedades, de que nos dá conta a dialética do trabalho ${ }^{(15)}$. É preciso também considerarmos as assimetrias de poder inscritas na própria linguagem, através das diversas formas de ideologia ${ }^{(20)}$, quando pensamos em efetiva comunicação.

Enquanto houver homens alienados e oprimidos nāo haverá verdadeira comunicação, uma vez que só "o Outro", em sua plena consciência e expressão, é capaz de fazer o indivíduo humano conhecer a si mesmo, reconhecer o caráter intersubjetivo que funda toda idéia humana acerca do homem ${ }^{(21)} \mathrm{e}$, portanto, todo projeto possível de uma vida não fracassada.

É evidente, nesse sentido, o caráter estratégico da epidemiologia. Se, contudo, ao apreender a dimensão coletiva dos processos de adoecimento, a epidemiologia continuar se abstendo do momento de síntese explicativa, 
possibilidades concretas de tornar objetivas as desigualdades nas condiçōes de vida das pessoas continuarāo sendo em grande medida desperdiçadas. Essas sínteses, desde que sejam capazes de expressar condições materiais e valores de quem explica e do que é explicado, podem se tornar poderosos meios de produção de efetivo diálogo sobre a saúde e a doença na sociedade, tanto no plano das práticas de conhecimento, que vimos discutindo, quanto no plano das práticas de intervenção sobre a doença na sociedade ${ }^{(23)}$.

Certamente a maneira de fazê-lo está longe de estar dada, não obstante as diversas e importantes iniciativas que vêm sendo experimentadas ao longo da história. Há, quanto a isto, somente uma certeza possível, hoje: a de que a epidemiologia, prática social e histórica, tem algo a dizer aos homens que ninguém poderá dizer em seu lugar.

\section{REFERÊNCIAS BIBLIOGRÁFICAS.}

1. ADORNO, T. W. La disputa del positivismoen la sociologia alemana Barcelona, Ediciones Grijalbo, 1973. p. 81-99: Introdución.

2. ALMEIDA FILHO, N. Epidemiologia sem números: uma introducăo crítica à ciência epidemiológica. Rio de Janeiro, Ed. Campus, 1989.

3. ALMEIDA FILHO, N. Paradigmas em epidemiologia. In: Congresso Brasileiro de Epidemiologia, 1, Campinas 1990. Anais. Rio de Janeiro, 1990, p. 329-46. 
4. AYRES, J.R.C.M. A epidemiologia e o projeto emancipador nas práticas de saúde: a crítica da razão instrumental na constituição histórica da ciência epidemiológica. São Paulo, 1991. [Dissertação de Mestrado - Faculdade de Medicina da USP]

5. AYRES, J.R.C.M. O problema do conhecimento verdadeiro na epidemiologia. Rev, Saúde Pública. S. Paulo, 26:206-14, 1992.

6. CANGUILHEM, G. Ideologia e racionalidade nas ciências da vida. Lisboa, Edições 70 , 1977, p. 21.

7. CANGUILHEM, G. La connaissance de la vie. Paris, Librairie Philosophique J. Vrin, 1985. p. 129-54: Le vivant et son milieu.

8. CANGUILHEM, G. Q normal e o patológico. Rio de Janeiro, Ed. Forense-Universitária, 1982.

9. DALMASO, A.S.W. Estruturação e transformação da prática médica: estudo de algumas das características do modelo de trabalho na segunda metade do século XIX e início do século XX. São Paulo, 1991. [Dissertação de Mestrado - Faculdade de Medicina da USP]

10. ENTRALGO, P.L. Historia de la medicina. Barcelona, Salvat, 1978.

11. FOUCAULT, M. As palavras e as coisas: uma arqueologia das ciências humanas. São Paulo, Ed. Martins Fontes, 1990.

12. FOUCAULT, M. O nascimento da clínica. Rio de Janeiro, Ed. Forense-Universitária, 1980.

13. HABERMAS, J. Pensamento pós-metafísico: estudos filosóficos. Rio de Janeiro, Tempo Brasileiro, 1990.

14. HABERMAS, J. Técnica e ciência como ideologia. Lisboa, Ediçōes 70, 1987. p. 11-43: Trabalho e interação.

15. HELLER, A. Teoria de las necessidades en Marx. Barcelona, Ediciones Península, 1986.

16. LUZ, M. T.Natural racional social - razão médica e racionalidade científica moderna. Rio de Janeiro, Ed. Campus, 1988. 
17. MENDES GONÇALVES, R.B. Contribuição sobre as relações entre teoria, objeto e método em epidemiologia. In: Congresso Brasileiro de Epidemiologia, $1^{\circ}$, Campinas, 1990. Anais. Rio de Janeiro, 1990, p. 346-61.

18. MENDES GONÇALVES, R. B. Reflexões sobre a articulação entre a investigação epidemiológica e a prática médica a propósito das doenças crônicas e degenerativas. In: Costa, D.C. org. Epidemiologia: teoria e objeto. São Paulo, Hucitec-Abrasco, 1990, p.39-86.

19. MENDES GONÇALVES, R. B. Tecnologia e organização social das práticas de saúde: características tecnológicas do processo de trabalho na rede estadual de centros de saúde de São Paulo. São Paulo, 1986. [Tese de Doutorado - Faculdade de Medicina da USP]

20. RICOEUR, P. Interpretacão e ideologias. Rio de Janeiro, Ed. Francisco Alves, 1988.

21. RICOEUR, P. O si mesmo como um outro Campinas, Ed. Papirus, 1991.

22. ROSEN, G. A history of public health. New York, MD Publications, 1976.

23. SCHRAIBER, L.B. Epidemiologia em serviços: uma tecnologia de que tipo? São Paulo, 1992. [mimeo]

24. SEMMELWEISS, I. Etiologia, conceito y profilaxis de la fiebre puerperal. In: Buck, C.; Llopis, A.; Nájera, E.; Terris, M. El desafío de la epidemiología: problemas y lecturas seleccionadas. Washington, 1988, p. 47-62. (OPAS - Publicación Científica N 505).

25. SNOW, J. Sobre a maneira de transmissão do cólera. São Paulo, Ed. Hucitec-Abrasco, 1990.

26. WHITEHEAD, A.N. A ciência e o mundo moderno São Paulo, Ed. Brasiliense, 1951. 